\title{
Acupuncture promotes white adipose tissue browning by inducing UCP1 expression on DIO mice
}

Weixing Shen ${ }^{1 \dagger}$, Yang Wang ${ }^{1 \dagger}$, Sheng-Feng Lu' ${ }^{1}$ Hao Hong ${ }^{1}$, Shuping Fu', Suyun He${ }^{1}$, Qian Li ${ }^{1}$, Jingxin Yue ${ }^{2}$, Bin $\mathrm{Xu}^{1 *}$ and Bing-Mei Zhu ${ }^{1 *}$

\begin{abstract}
Background: To study the influence of acupuncture and its possible mechanism on white adipose tissue of high fat diet-induced obese.

Methods: Four-week-old C57BL/6 J mice were randomly divided into a normal diet group and a high-fat diet (HFD) group. After 8 weeks, the HFD mice were randomly divided into Electro-acupuncture (EA) group and control group. Mice in the EA group were electro-acupunctured, under physical restraint, on Zusanli (ST36) and Neiting (ST44) acupoints, while the mice in the control group were under physical restraint only. Body weight and food intake were monitored, and serum leptin, cholesterol and triglyceride levels were measured by using biochemistrical methods. The effect of EA on white adipose tissues (WAT) was assessed by qPCR, immunobloting, immunohistochemistry $(\mathrm{IHC})$, immunoprecipitation and cold endurance experiment.

Results: The WAT/body weight ratio decreased $(P<0.05)$ in the EA group, albeit no significant difference on food consumption between EA and control groups. The difference in the darkness of Epi-WAT between EA and control groups could be distinguished visually. HE staining indicated that the EA mice had an increased number of UCP1-immunoreactive paucilocular adipocytes in their WAT. The expressions of brown adipose tissue (BAT) markers, including UCP1, COX4il and Nrtf1 were increased in the WAT of EA mice, acetylation of Ppary was decreased by electro-acupuncture.
\end{abstract}

Conclusion: EA can remodel WAT to BAT through inducing UCP1 expression, and this may be one of the mechanisms by which acupuncture affects weight loss.

Keywords: Acupuncture, Browning, Obesity, UCP1, White adipose tissue

\section{Background}

Obesity is one of the leading global health risk factors and is associated with other health concerns, such as type 2 diabetes mellitus, cardiovascular diseases, and cancer. In high-risk subjects, a 5-10\% reduction in body weight can lower the risk of diabetes by $58 \%$ [1]. Existing anti-obesity drugs and therapies have been limited by side effects including mood changes, suicidal thoughts, and gastrointestinal or cardiovascular complications, and

\footnotetext{
*Correspondence: xuuuux@sina.com; zhubm64@hotmail.com

${ }^{\dagger}$ Equal contributors

'Key Laboratory of Acupuncture and Medicine Research of Ministry of Education, Nanjing University of Chinese Medicine, 210023 Nanjing, China Full list of author information is available at the end of the article
}

have also failed to achieve adequate weight control in all patients [2]. In this way, obesity has become a modernday medical challenge.

Obesity results from chronic excess energy intake over energy expenditure. Its progression is controlled by variable and complex interactions between genetic background, environmental factors, behavioral factors, and socioeconomic status. In periods of excess caloric intake, energy is accumulated mainly in the white adipocytes of white adipose tissue (WAT), in the form of triacylglycerols that can be mobilized when needed, releasing fatty acids into the blood stream. Brown adipose tissue (BAT) is different from WAT at a functional, morphological, and molecular level. BAT dissipates energy directly as

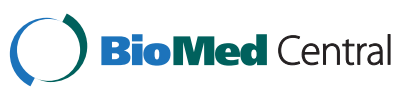

(c) 2014 Shen et al.; licensee BioMed Central. This is an Open Access article distributed under the terms of the Creative Commons Attribution License (http://creativecommons.org/licenses/by/2.0), which permits unrestricted use, distribution, and reproduction in any medium, provided the original work is properly credited. The Creative Commons Public Domain Dedication waiver (http://creativecommons.org/publicdomain/zero/1.0/) applies to the data made available in this article unless otherwise stated. 
heat by uncoupling fatty acid oxidation from ATP production via uncoupling protein-1(UCP1), which is characteristically expressed in the mitochondrial inner membrane of brown adipocytes and, when activated, uncouples the oxidation of fuel substrates from the production of ATP, thus generating heat [3]. UCP1 is also vital for the regulation of body temperature [4], and is involved in the control of body weight [5]. Recently, inducible brown-like adipocytes from white adipose tissue, in response to appropriate stimulation, have become the target of many obesity therapeutics [6-9]. Novel approaches using specific drugs or other stimulations to induce a program of brown fat differentiation, including UCP1 expression and enhanced oxidative metabolism, in white adipose cells are expected to be on the rise.

For many years, acupuncture has been used to treat obesity in China and has been studied in clinical trial around the world [10-12]. It provides a safe and effective alternative therapy, gaining increased acceptance by obesity patients as their treatment of choice, as well as recognition by both the National Institutes of Health and the WHO. However, the mechanism by which acupuncture targets obesity still remains unclear.

Does electro-acupuncture (EA) stimulation induce WAT "browning"? In the present study, we employed diet induced obese mice as the animal model, and treated them with EA on Zusanli (ST36) and Neiting (ST44) acupoints. Our study, for the first time, revealed that electroacupuncture treatment could induce UCP1 expression in WAT and promote browning of WAT.

\section{Methods}

\section{Antibodies and primers}

Antibodies

Goatanti-UCP1 (Santa Cruz, Cat\#sc-6528, 1:500 dilution for Western Blot); Rabbit anti-Prdm16 (Abcam, Cat\#ab106410, 1:1000 dilution for Western Blot); Rabbit anti-SirT1 (Abcam, Cat\#ab32441, 1:1000 dilution for Western Blot); Rabbit anti-GAPDH (Cell Signaling, Cat\#2118, 1:2000 dilution for Western Blot); Rabbit anti-Ppary for western blot (Cell Signaling, Cat\#2443, 1:1000 dilution for Western Blot); Mouse anti-Ppary for immunoprecipitation (Santa Cruz, Cat\#sc-7273); Mose anti-Acetyl-Lycine (Cell Signaling, Cat\#05-515, 1:1000 dilution for Western Blot).

\section{Primers}

Primers were designed using Primer 5.0 software. UCP1 (forward: 5' -TGGAAAGGGACGACCCCTAA-3', Reverse: 5' -CAGGAGTGTGGTGCAAAACC-3'), Prdm16 (Forward: 5' -CTTAGCCGGGAAGTCACAGG-3', Reverse: 5' -CCTCAACACACCTCCGGGTA-3'), Ppary (Forward: 5'-GTCACACTCTGACAGGAGCC-3', Reverse: 5'-CAC CGCTTCTTTCAAATCTTGT-3'), GAPDH (Forward:
5' -AAGGGCTCATGACCACAGTC-3', Reverse: 5' -CAG GGATGATGTTCTGGGCA-3').

\section{Animals and grouping}

Four-week-old C57BL/6J mice $(\mathrm{n}=100)$ were supplied by the Experimental Animal Center of Nanjing University of Chinese Medicine, and were randomly divided into normal diet group (NF, $\mathrm{n}=20$ ) and high-diet food group (HDF, $\mathrm{n}=80$ ). Mice in NF group were fed a normal diet, and mice in HDF group were fed D12451 Rodent Diet with $45 \mathrm{kcal} \%$ Fat (purchased from Shanghai SLAC Laboratory animal Co. Ltd). Mice were weighted each week after fasting for eight hours. After eight weeks, obese mice were defined by a $20 \%$ increase in body weight compared to the NF mice, and were then randomly divided into control group and Electro-acupuncture group (EA). The study was approved by the Institutional Animal Care and Use Committee of Nanjing University of Chinese Medicine, and all procedures were conducted in accordance with the guidelines of the National Institutes of Health Animal Care and Use Committee.

\section{Electro-Acupuncture intervention}

Mice in the EA group were physically restrained, then electro-acupunctured on Zusanli (ST36) and Neiting (ST44), while mice in the control group were restrained in the same way, without acupuncture. For the EA mice, two acupuncture needles (Gauge-28, $0.5 \mathrm{~cm}$ ) were separately inserted into each acupoint and an electrical current was provided to the needles through an electrical stimulator with parameters of $2 / 15 \mathrm{~Hz}$ at an intensity level of $1 \mathrm{~mA}$ (Han Acuten, WQ1002F, Beijing, China) for $30 \mathrm{mi}-$ nutes, once a day, six days a week. Mice body weight and food consumption were monitored every week. After 4 weeks of EA treatment, all of mice were sacrificed with $\mathrm{CO}_{2}$ and samples were collected.

\section{qPCR analysis}

Total RNA was isolated using TRIzol $^{\circledR}$ Reagent (Invitrogen, Cat\#15596-026) according to the manufacturer's recommendations. RNA concentrations were quantified and reverse-transcribed using ThermoScript ${ }^{\mathrm{Tm}}$ RT-PCR System for First-Strand cDNA Synthesis (Invitrogen, Cat\#11146016). Gene expressions were detected using GoTaq qPCR Master Mix (Promega, Cat\#A6001) in Strata gene MX3000P Real-Time PCR system (Genetimes, China). Relative gene expression levels were calculated by $\Delta \Delta \mathrm{Ct}$ and compared with GAPDH as internal control.

\section{Immunoblotting}

Samples in SDS Loading Buffer were heated $\left(100^{\circ} \mathrm{C}\right.$, $5 \mathrm{~min}$ ), subjected to SDS-PAGE, transferred to PVDF or nitrocellulose membranes, and blocked ( $4^{\circ} \mathrm{C}$, overnight) in PBST (PBS with $0.05 \%$ Tween 20) containing 5\% non-fat 
dry milk or $5 \%$ BSA. Blots were incubated with a primary antibody in blocking buffer (overnight, $4^{\circ} \mathrm{C}$ ), and then with a second antibody $(1: 1000 \sim 2000$ dilution, $1 \mathrm{~h}, \mathrm{RT})$. Signals were detected using SuperSignal ${ }^{\circ}$ West Femto Maximum Sensitivity Substrate. Immunodetection of endogenous GAPDH was utilized to indicate that equivalent amounts of protein were present in samples added to the SDS PAGE (wells/lanes. $\mu \mathrm{g} / \mathrm{L}$ ).

\section{Immunoprecipitation}

Rat epididymal adipose tissue were homogenized in icecold buffer containing $10 \%$ glycerol with $\mathrm{mmol} / \mathrm{L}$ of 50 HEPES, 100 sodium pyrophosphate, 100 sodium fluoride, 1 EDTA, 1X Protease inhibitor cocktail (Sigma, Cat\# P8340) and $1 \%$ Triton X-100 or 1\% NP-40. Insoluble material was removed by centrifugation $(100,000 \mathrm{~g}$, $\left.30 \mathrm{~min}, 4^{\circ} \mathrm{C}\right)$. Pre-cleared lysates $(500 \mu \mathrm{g})$ were incubated (overnight, $4^{\circ} \mathrm{C}$ ) with $2 \mu \mathrm{g}$ anti-Ppary (Santa Cruz). Protein $\mathrm{G}$ beads were added; After incubated for 2 hours at $4^{\circ} \mathrm{C}$, the beads were centrifuged $(2,000 \mathrm{~g}, 30 \mathrm{~s})$, washed 5 times with ice-cold lysis buffer, and heated in $1 \times$ SDS sample buffer containing $5 \% \beta$-mercaptoethanol at $95^{\circ} \mathrm{C}$ for 5 minutes to release bound protein. Eluates were subjected to SDS-PAGE for Western blot.

\section{Elisa detection of serum leptin, cholesterol and triglyceride level}

Elisa kit were purchased from ShangHaiQiaDu Biotechnology CO.LTD, Leptin (Cat\# QD20613), cholesterol (Cat\#QD20142) and Triglyceride (Cat\# QD20195). Serum level were detected according to the manufacturer's recommendations. Briefly, standards and each $40 \mu \mathrm{l}$ of mice serum was added into 96 well coated plate with $10 \mu \mathrm{l}$ biotin labeled antibody, incubated at $37^{\circ} \mathrm{C}$ for $30 \mathrm{~min}$ and followed with 5 times washing, then incubated with HRPConjugate reagent for $60 \mathrm{~min}$ at $37^{\circ} \mathrm{C}$. Washed 5 times, then add Chromogen solution A $50 \mu \mathrm{l}$ and Chromogen solution $\mathrm{B}$, evade the light preservation for $15 \mathrm{~min}$ at $37^{\circ} \mathrm{C}$, $50 \mu \mathrm{l}$ stop solution were added, OD values were detected at $450 \mathrm{~nm}$ by using Multiskan FC (Thermo scientific, USA). Leptin, cholesterol and triglyceride level were quantified by standard curve.

\section{Histological analysis and Immunofluorescence staining}

Adipose tissue was fixed with $4 \%$ formalin and embedded with paraffin, sliced to $25 \mu \mathrm{m}$ thickness sections on glass slides, dewaxed in xylene $(5 \times 4 \mathrm{~min})$, and hydrated (100\%, 95\% and $75 \%$ ethanol) for $2 \times 3$ minutes each. Slides were heated in a microwave for $3 \times 5 \mathrm{~min}$ in target antigen retrieval solution (Dako), cooled down to room temperature, washed in PBS ( $3 \times 5 \mathrm{~min})$, and blocked and permeabilized in $10 \%$ donkey serum containing $0 . \%$ triton $\mathrm{X}-100$ for $6 \mathrm{~h}$ at $4^{\circ} \mathrm{C}$. Slides were incubated in blocking buffer with a primary antibody overnight, and washed with
PBS ( $3 \times 5 \mathrm{~min}$ ) before incubating in blocking buffer for two hours with secondary antibodies (Alexa Fluor 488 or Alexa Fluor 594) (Molecular Probes). Slides were viewed with a fluorescence microscope (Nikon TE2000, Japan).

\section{Mice cold endurance experiment}

Mice were left in their cage without any padding, food and water in a $4^{\circ} \mathrm{C}$ cold room. Rectal temperatures were detected by using an electro-thermometer (TH212, Hongauchengyun Co. Ltd., China) every three hours.

\section{Statistics}

Data were presented as means \pm standard deviation (SD). Statistics analysis was performed using SPSS 18.0; multiple group comparisons were made by ANOVA, and two group comparison was determined using unpaired 2 -tailed Student's t test. $P<0.05$ was considered statistically significant.

\section{Results}

Electro-acupuncture significantly reduced the ratio of the weight of WAT to body weight

Acupuncture has been used for weight control both clinically and experimentally for many years in China and in other countries [10-13]. However, in this study, electroacupuncture on Zusanli (ST36) and Neiting (ST44) did not markedly reduce the body weight or the food intake of DIO mice compared with the mice without acupuncture treatment (Figure 1A, 1B), even after five weeks of intervention. For the first three weeks of treatment, mice in both EA and control groups showed a decrease in appetite, which, however, began to decreased by the fifth week of treatment in control mice but continued to increase in EA mice, suggesting that electro-acupuncture enhanced appetite in these mice to a certain extent.

The above observations raised a question: how did electro-acupuncture affect obese mice without significantly reducing body weight or food intake? We isolated mice-epididymal white adipose tissue and inguinal white adipose tissue from the mice in the NF, control, and EA groups, and calculated the ratio of Epi-WAT and IniWAT to their body weight. We found that in mice fed a high fat diet, the ratio was significantly higher than that in mice fed normal food. In addition, five weeks of treatment with electro-acupuncture significantly decreased these ratios (Figure 1C, 1D). Our data suggest that the effectiveness of electro-acupuncture on obesity maybe due to the reduction in the ratio of weight of WAT/body weight.

\section{Electro-acupuncture induced UCP1 expression promoted WAT browning}

Un-coupling protein 1 (UCP1) gene is usually specifically expressed in brown adipose tissue (BAT) and is 




regarded as a BAT marker. In this study, after a fiveweek treatment with electro-acupuncture, the WAT in EA mice looked grossly darker compared to that in the untreated control mice (Figure 2C), which hinted that electro-acupuncture may promoted WAT to change to BAT. We also found that UCP1 gene expression in WAT increased almost 14 folds in EA mice than in the control mice (Figure 2A), and the UCP1 protein expression also significantly increased in EA mice (Figure 2B). Our data strongly suggests that electro-acupuncture treatment results in browning of WAT in EA mice. Because UCP1 is mainly responsible for thermogenic actions and lipid mobilization in mammals, we analyzed adipocyte size via immunohistochemistry and observed obviously smaller size of the WAT in EA mice compared with the control mice and normal food mice (Figure 2D), suggesting that electro-acupuncture treatment might promote lipolysis in obesity mice.

\section{Electro-acupuncture treatment increased the ability of} cold endurance

To further examine the thermogenesis of mice, four mice from each group were subjected to cold endurance experiment. After exposed to $4^{\circ} \mathrm{C}$ for six hours, the rectal temperatures of mice that received electro-acupuncture treatment were markedly higher than that of the control mice (Figure 3D), suggesting that EA mice were more able to bear the cold stimulation, compared with the control mice. Combined with the UCP1 expression data, our results suggested that the browning of WAT in the EA mice might be responsible for the generation of more heat to maintain body temperature.

Electro-acupuncture treatment significantly reversed serum leptin, cholesterol, and triglyceride level of obesity mice Leptin production can be spontaneously increased by adipocyte in response to excess body fat. Cholesterol 


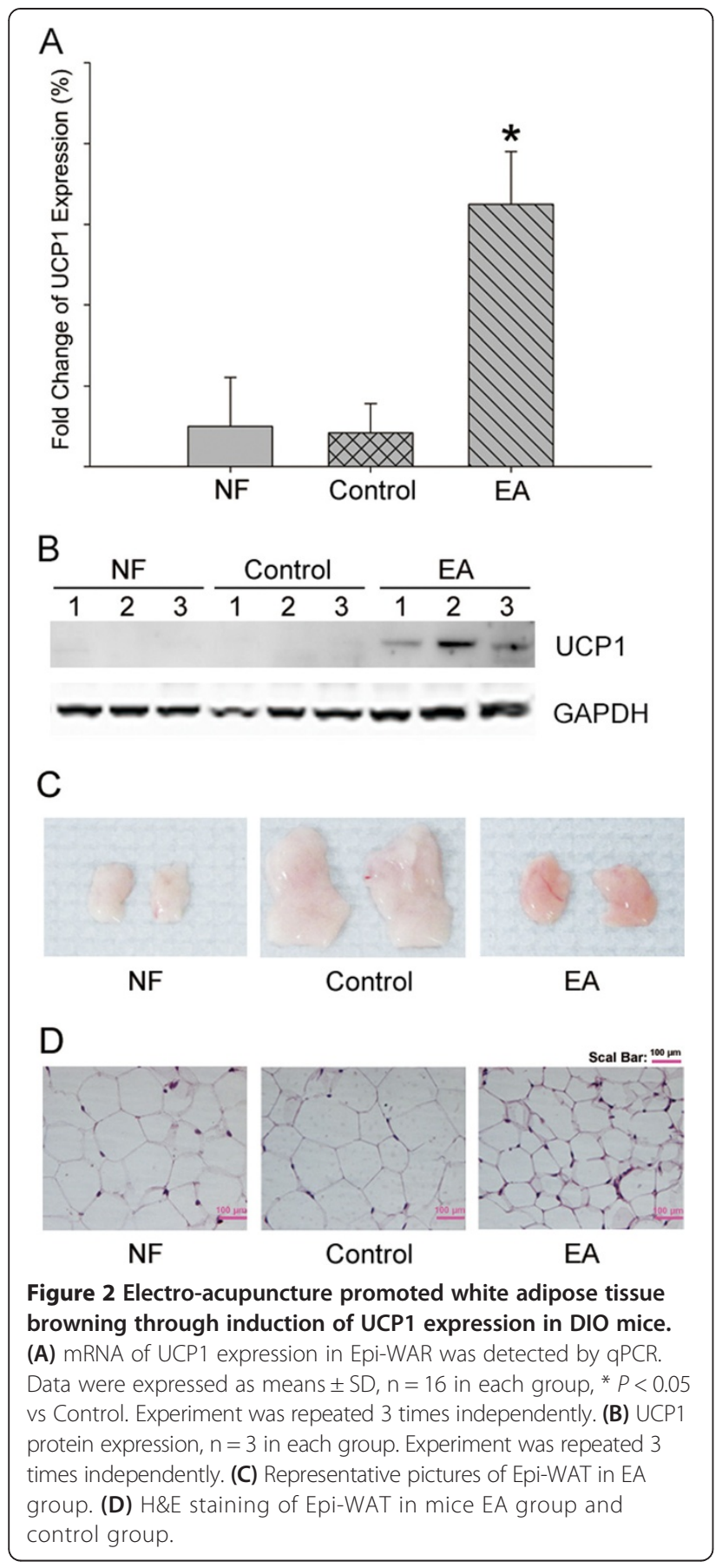

and triglyceride also increase in serum when there is abundant lipid in the tissues. Serum level of leptin, cholesterol, and TG were detected by ELISA kit, and we found that compared with mice that were fed normal food leptin, cholesterol, and TG level were all significantly elevated in obese mice after consuming high fat diet for eight weeks; however, five weeks of treatment with electro-acupuncture completely reversed these levels to normal, just as in the NF mice (Figure 3A, 3B and $3 \mathrm{C}$ ).
Our data suggested that electro-acupuncture effectively reduced the lipid content in obese mice.

Electro-acupuncture treatment changed BAT-related gene expression and Ppary acetylation in WAT

Transcription of UCP1 is regulated by a series of molecular mechanisms, in which Ppary, SirT1, and Prdm16 are involved. We found that the gene expression of Ppary increased 1.5 fold in WAT of EA mice than in the control mice (Figure 4A), though its protein level did not change (Figure 4D), but the acetylation of Ppary was obviously decreased in EA mice after electro-acupuncture treatment (Figure 4E). Prdm16, which is a co-activator of Ppary regulating UCP1 transcription, did not show any difference in expression levels between the EA and the control groups (Figure 4D). SirT1, which encodes Sirt1 protein and regulates UCP1 expression through histone deacetylation [7], was elevated at the protein level in the EA group (Figure 4D). Unsurprisingly, the gene expressions of other two specific BAT markers, COX4il (Figure 4B) and Nrbf1 (Figure 4C), increased significantly in WAT of EA mice, compared with that of the control mice. These data confirmed, once again, that electro-acupuncture promoted WAT browning.

\section{Discussion}

Obesity is one of the leading global health risk factors, since 1.1 billion people worldwide $(>10 \%$ of the world population) are classified as overweight [14-16]. Current conventional therapeutic strategies for obesity, including caloric restriction, physical exercise, and drugs, however, can't effectively achieve adequate weight control. Although exercise can result in short-term weight loss, only $5-10 \%$ of subjects can maintain the weight loss for more than a few years [17], and the use of drugs such as Sibutramine, Rimonabant and Orlistat is limited in obesity treatments due to their side effects on the cardiovascular system. Acupuncture is among the oldest healing practices in the world [18]. It exerts its effect through the insertion of thin metallic needles at specific points on the body, and is one of the most rapidly growing complementary therapies. Even in animal models such as obese rats, electro-acupuncture can reduced their body weight $[13,19]$. However, our results don't show a significant reduction in body weight after acupuncture treatment in DIO mice (Figure 1A). A decrease in appetite as a result of acupuncture has been thought as one of the reasons for weight loss in obese mice [13,20], however on the contrary, we don't see a significant difference in food intake between the mice with and without electro-acupuncture treatment, and even find a slightly increased food consumption in the EA mice (Figure 1B). Interestingly, the ratio of the weight of WAT, which is a major tissue for excess energy storage, to body weight 


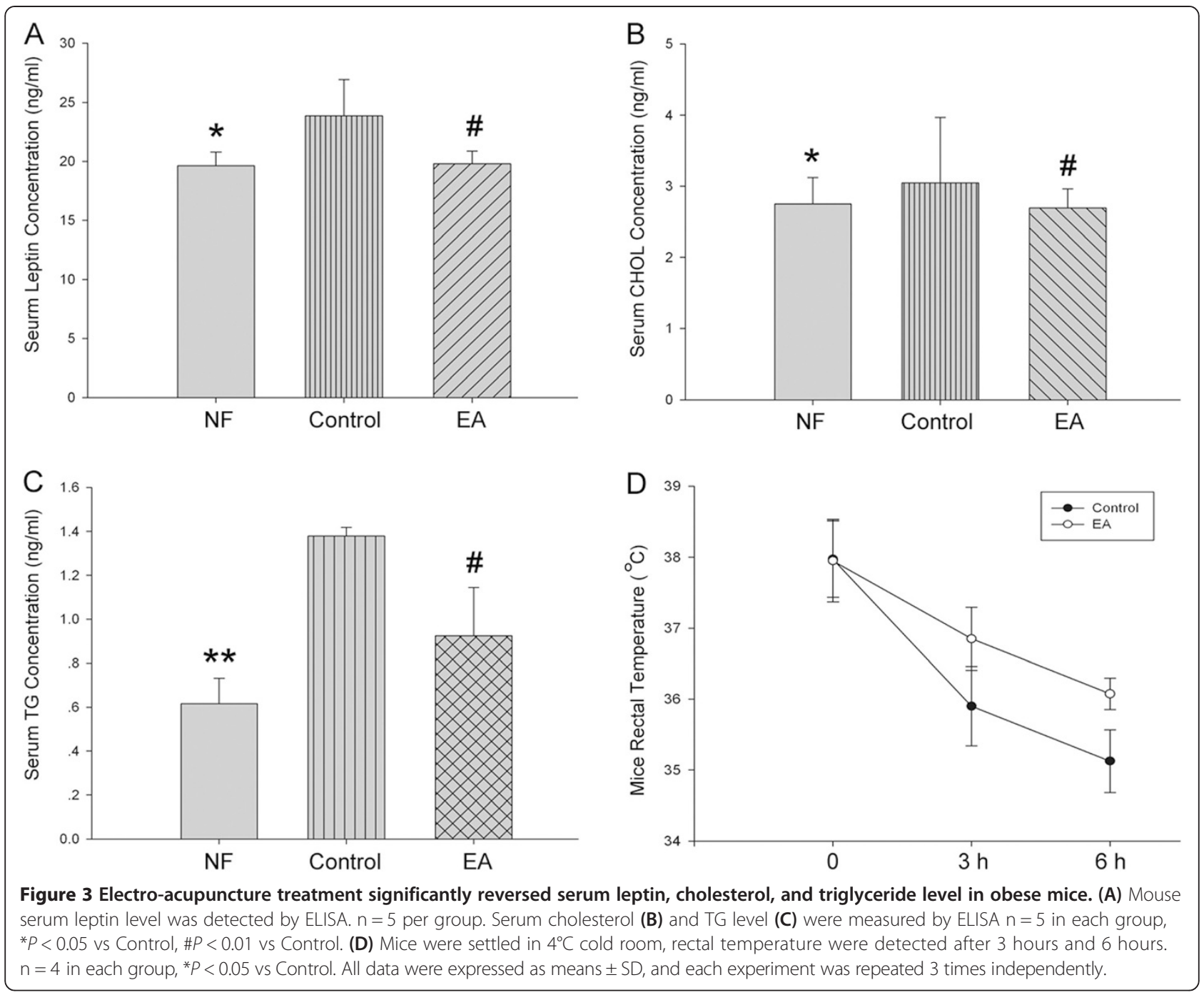

significant decreases following electro-acupuncture, both for Epi-WAT (Figure 1C) and Ini-WAT (Figure 1D). We suspect that acupuncture treatment promotes WAT lipolysis and restricts adipose tissue synthesis. Thus, this maybe a possible mechanism by which acupuncture can be used to target obesity.

An important characteristic of WAT browning is the over-expression of UCP1, which is seen specifically in BAT. Brown adipocytes uncouple mitochondrial electron transport from ATP synthesis to a greater extent than other cells do by permeabilizing the inner mitochondrial membrane to allow inter-membrane proton to leak back into the mitochondrial matrix, primarily through uncoupling protein-1 (Ucp1) [3] to dissipates energy as heat (nonshivering thermogenesis). Browning of WAT can be brought about by hormones, cytokines, and transcriptional modulation [21-23]. Our results show that five weeks of treatment with electro-acupuncture on Zusanli (ST36) and Neiting (ST44) acupoints can remodel
WAT to BAT in obese mice through inducing UCP1 expression (Figure 2A, 2C), thus promoting WAT lipolysis and decreasing adipocyte size as shown in Figure 2D. Since UCP1 is responsible for energy dissipation via nonshivering thermogenesis, under cold circumstances mice with more UCP1 expression can more efficiently generate heat to maintain body temperature as shown in Figure 3D. Also, with the WAT converting to BAT, serum level of leptin is significantly decreased (Figure $3 \mathrm{~A}$ ), as well as TG and cholesterol levels (Figure 3B, 3C). Our experiment, for the first time, provides the evidence of WAT browning by electro-acupuncture on obese mice.

It has recently been reported that activation of the nuclear receptor Ppary by TZDs such as Rosiglitazone could also induce a brown-like phenotype in white adipocytes through promoting expression of brown adipocyte specific genes (brown genes) and suppressing visceral WAT genes (white genes) [24]. UCP1 expression is regulated by Ppary binding on UCP1 enhancer. SirT1-dependent deacetylation 


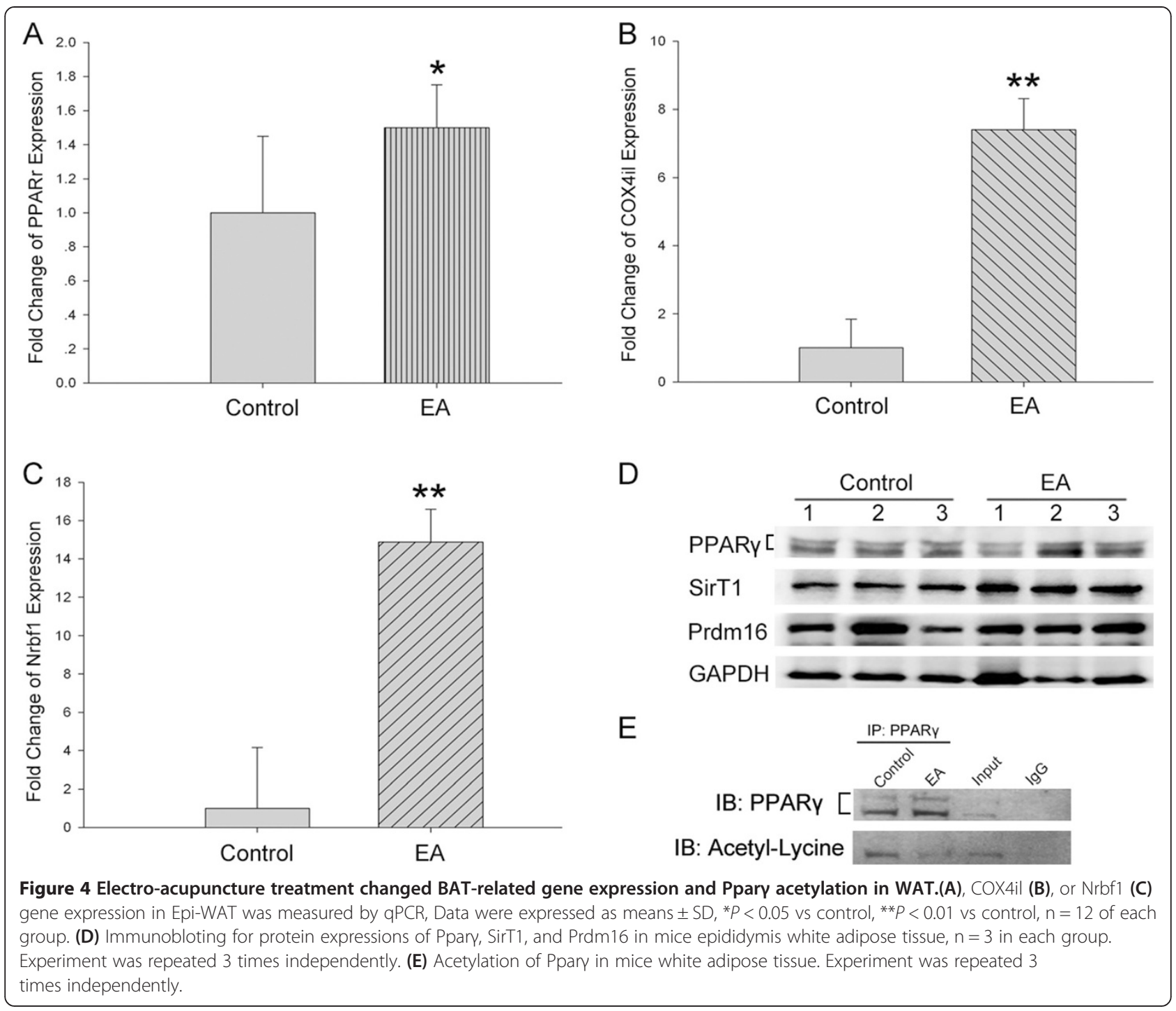

of Lys268 and Lys293 is required to recruit the BAT program co-activator Prdm16 to Ppary, leading to selective induction of BAT genes and repression of visceral WAT genes associated with insulin resistance [7]. These findings are consistent with our experiment; in addition WAT browning, expression of Ppary gene also significantly increase in WAT due to electro-acupuncture treatment (Figure 4A), but not in protein level (Figure 4D). Furthermore, we found the acetylation of Ppary was obviously decreased in EA mice by the electro-acupuncture treatment (Figure 4E), this data suggest acupuncture might promote Ppary deacetylation to increase UCP1 gene expression then inducing WAT browning. Moreover, other BAT markers such as Nrbf1 and Cox4il, are also notably elevated by electro-acupuncture (Figure 4B, 4C). Although, we found the electro-acupuncture could promote WAT browning and weight loss in obese mice, the detailed mechanisms by which the effectiveness exerted at the cellular level stay unclear. Further studies in the animal models and clinical patients are of interest.

\section{Conclusions}

Taking together, our results firstly gave the experimental evidence that EA can remodel WAT to BAT through inducing UCP1 expression, and this may be one of the mechanisms by which acupuncture affects weight loss.

\section{Abbreviations}

BAT: Brown adipose tissue; DIO: Diet-induced obesity; EA: Electro-acupuncture; UCP1: Uncouplingprotein-1; WAT: White adipose tissue.

\section{Competing interests}

The authors have declared that no competing interests exist.

\section{Authors' contributions}

WXS did experiments and wrote the manuscript; $Y$ W did experiments and analyzed data; $\mathrm{H} \mathrm{H}$ did the animal experiments; SPF did the part of $\mathrm{qPCR}$ 
experiments; BX and SFL directed the acupuncture treatment; $\mathrm{Q} L$ did the immunohistochemistry experiment; $Y \mathrm{~S}$ and $\mathrm{Y} \mathrm{H}$ did part of the molecular experiments; B-M Z designed the experiments and wrote the manuscript. All authors read and approved the final manuscript.

\section{Acknowledgements}

This work was supported by National Basic Research Program of China (973 program, Grand No.2012CB518501), the National Natural Science Foundation of China (Grant No. 81273838, 81303018, 81303019), the National Natural Science Foundation of Jiangsu colleges and universities (Grant No. 11KJA360003), the Nanjing University of TCM (Grand No. YS2012ZTX411).We also thank WX LIU (University of Pennsylvania School of Veterinary Medicine) for editing of English.

\section{Author details}

${ }^{1}$ Key Laboratory of Acupuncture and Medicine Research of Ministry of Education, Nanjing University of Chinese Medicine, 210023 Nanjing, China. ${ }^{2}$ School of Information Technology, Nanjing University of Chinese Medicine, 210023 Nanjing, China.

Received: 23 January 2014 Accepted: 11 December 2014 Published: 16 December 2014

\section{References}

1. Knowler WC, Barrett-Connor E, Fowler SE, Hamman RF, Lachin JM, Walker EA, Nathan DM: Diabetes Prevention Program Research Group: Reduction in the incidence of type 2 diabetes with lifestyle intervention or metformin N Engl J Med 2002, 346(6):393-403.

2. Wang YC, McPherson K, Marsh T, Gortmaker SL, Brown M: Health and economic burden of the projected obesity trends in the USA and the UK. Lancet 2011, 378(9793):815-825.

3. Ravussin E, Galgani JE: The implication of brown adipose tissue for humans. Annu Rev Nutr 2011, 31:33-47.

4. Enerbäck S, Jacobsson J, Simpson EM, Guerra C, Yamashita H, Harper ME, Kozak LP: Mice lacking mitochondrial uncoupling protein are cold-sensitive but not obese. Nature 1997, 387(6628):90-94.

5. Feldmann HM, Golozoubova V, Cannon B, Nedergaard J: UCP1 ablation induces obesity and abolishes diet-induced thermogenesis in mice exempt from thermal stress by living at thermoneutrality. Cell Metab 2009, 9(2):203-209.

6. Farmer SR: Obesity: Be cool, lose weight. Nature 2009, 458(7240):839-840.

7. Qiang L, Wang L, Kon N, Zhao W, Lee S, Zhang Y, Rosenbaum M, Zhao Y, Gu W, Farmer SR, Accili D: Brown remodeling of white adipose tissue by SirT1-dependent deacetylation of Ppary. Cell 2012, 150(3):620-632.

8. Cao L, Choi EY, Liu X, Martin A, Wang C, Xu X, During MJ: White to brown fat phenotypic switch induced by genetic and environmental activation of a hypothalamic-adipocyte axis. Cell Metab 2011, 14(3):324-338.

9. LP K: Brown fat and the myth of diet-induced thermogenesis. Cell Metab 2010, 11(4):263-267

10. Darbandi S, Darbandi M, Mokarram P, Owji AA, Zhao B, Ghayor-Mobarhan M, Abdi H, Saberfiroozi M, Nematy M, Safarian M, Parizadeh MR, Shakeri MT, Soukhtanloo M, Abbasi P, Salehmoghadam M, Dabbaghmanesh MH, Ferns G: Effects of body electroacupuncture on plasma leptin concentrations in obese and overweight people in Iran: a randomized controlled trial. Altern Ther Health Med 2013, 19(2):24-31.

11. L R: Efficacy of auricular acupressure combined with transcutaneous electrical acupoint stimulation for weight reduction in obese women J Med Assoc Thai 2012, 95(Suppl 12):S32-S39.

12. Wang Q, Li WH, Zhou QH, Tang XD, Zhang XX, Shu S: Weight reduction effects of acupuncture for obese women with or without perimenopausal syndrome: a pilot observational study. Am J Chin Med 2012, 40(6):1157-1166.

13. Fei Wang, Tian de R, Tso P, Han JS: Arcuate nucleus of hypothalamus is involved in mediating the satiety effect of electroacupuncture in obese rats. Peptides 2011, 32(12):2394-2399.

14. Monteiro CA, Moura EC, Conde WL, Popkin BM: Socioeconomic status and obesity in adult populations of developing countries: a review. Bull World Health Organ 2004, 82(12):940-946.

15. Haslam DW, James WP: Obesity. Lancet 2005, 366:1197-1209.
16. Yach D, Hawkes C, Gould CL, Hofman KJ: The global burden of chronic diseases: overcoming impediments to prevention and control. JAMA 2004 291(21):2616-2622.

17. AN H: The historical development, efficacy and safety of very-low-calorie diets. Int J Obes 1981, 5:195-208. 3.

18. Ulett GA, Han S, Han JS: NIH Consensus Development Panel. Acupunct JAMA 1998, 280:1518-1524.

19. Gong M, Wang X, Mao Z, Shao Q, Xiang X, Xu B: Effect of electroacupuncture on leptin resistance in rats with diet-induced obesity. Am J Chin Med 2012, 40(3):511-520.

20. Tian N, Wang F, Tian DR, Zou Y, Wang SW, Guan LL, Shi YS, Chang JK, Yang J, Han JS: Electroacupuncture suppresses expression of gastric ghrelin and hypothalamic NPY in chronic food restricted rats. Peptides 2006, 27(9):2313-2320

21. Boström $P$, Wu J, Jedrychowski MP, Korde A, Ye L, Lo JC, Rasbach KA Boström EA, Choi JH, Long JZ, Kajimura S, Zingaretti MC, Vind BF, Tu H, Cinti S, Højlund K, Gygi SP, Spiegelman BM: A PGC1-a-dependent myokine that drives brown-fat-like development of white fat and thermogenesis. Nature 2012, 481(7382):463-468

22. Seale P, Conroe HM, Estall J, Kajimura S, Frontini A, Ishibashi J, Cohen P, Cinti S, Spiegelman BM: Prdm16 determines the thermogenic program of subcutaneous white adipose tissue in mice. J Clin Invest 2011, 121(1):96-105.

23. Fisher FM, Kleiner S, Douris N, Fox EC, Mepani RJ, Verdeguer F, Wu J, Kharitonenkov A, Flier JS, Maratos-Flier E, Spiegelman BM: FGF21 regulates PGC-1 $\mathrm{a}$ and browning of white adipose tissues in adaptive thermogenesis. Genes Dev 2012, 26(3):271-281.

24. Vernochet C, Peres SB, Davis KE, McDonald ME, Qiang L, Wang H, Scherer PE, Farmer SR: C/EBPalpha and the corepressors CtBP1 and $\mathrm{CtBP2}$ regulate repression of select visceral white adipose genes during induction of the brown phenotype in white adipocytes by peroxisome proliferator-activated receptor gamma agonists. Mol Cell Biol 2009, 29(17):4714-4728

doi:10.1186/1472-6882-14-501

Cite this article as: Shen et al:: Acupuncture promotes white adipose tissue browning by inducing UCP1 expression on DIO mice. BMC Complementary and Alternative Medicine 2014 14:501.

\section{Submit your next manuscript to BioMed Central and take full advantage of:}

- Convenient online submission

- Thorough peer review

- No space constraints or color figure charges

- Immediate publication on acceptance

- Inclusion in PubMed, CAS, Scopus and Google Scholar

- Research which is freely available for redistribution 